\title{
Sex Differentiation by Lip Print Analysis in Malays: Lipstick- Cellophane Tape Techniques
}

\author{
Wan Rafiuddin Wan Ahmad, Sri Pawita Albakri Amir Hamzah, Noor Hazfalinda Hamzah* \\ Forensic Science Program, Faculty of Health Science, Universiti Kebangsaan Malaysia, Jalan Raja Muda \\ Abdul Aziz, 50300 Kuala Lumpur, Malaysia
}

\begin{abstract}
*Corresponding Author: Noor Hazfalinda Hamzah, Forensic Science Program, Faculty of Health Science, Universiti Kebangsaan Malaysia, Jalan Raja Muda Abdul Aziz, 50300 Kuala Lumpur, Malaysia, Email: raviera@yahoo.com
\end{abstract}

\begin{abstract}
Generally, fingerprint, hair, and lip print are examples of trace evidence that can be found in most crime scenes. Lip print can also be used as identification because itis unique.This study was designed to differentiate sex based on lip print patterns among Malay population using lipstick-cellophane tape technique using the Suzuki and Tsuchihashi classification. Six topography areas of lip prints were classified into upper left, upper middle, upper right, lower right, lower middle and lower left. 360 subjects (180 males and 180 females) among Malay population were selected conveniently. The result showed that there were significant differences between male and female in all sections where $p<0.05$. Type II were the dominant lip print patterns for both sex in four sections: upper left (28.9\% for male and $58.9 \%$ for female), upper right (35.6\% for male and $48.3 \%$ for female), lower right (45.0\% for male and $58.9 \%$ for female) and lower left (55.0\% for male and $65.0 \%$ for female) while type IV lip print patterns was the dominant for upper middle section (61.7\% for male and $46.1 \%$ for female) and lower middle (50.0\% for male and $33.9 \%$ for female).
\end{abstract}

Keywords: Cheiloscopy, classification, sex determination, lip print, lipstick-cellophane technique

\section{INTRODUCTION}

Cheiloscopy is a method of personal identification based on the arrangement of lines or grooves appearing on the red part of the lips [1]. Lip prints are considered to be a new method that can adjudicate personal identification in criminal search and genetic studies [2]. Fingerprints and lip prints are permanent and inalterable over time unless there is a pathology which can affect the lips and fingers [3, 4]. Cheiloscopy can also be used in gender and races determination [5]. Lip prints are considered to be important evidence which may be found on cigarettes butt, or drinking glass whether they are visible or not [6].

Suzuki and Tsuchihashi classifications was selected for this research because it was widely used classification in literature [4]. Figure 1 shows six types of lip prints based on its shape and type of grooves in Suzuki and Tsuchihashi classification [7]. Type I; linear vertical grooves across the lip, type I'; linear vertical grooves but disappear half-way of the lip, type II; branches grooves, type III; intersect grooves, type IV; the grooves are horizontal and finally type V; the grooves do not match into any of the types I-IV and cannot be distinguish morphologically [2].

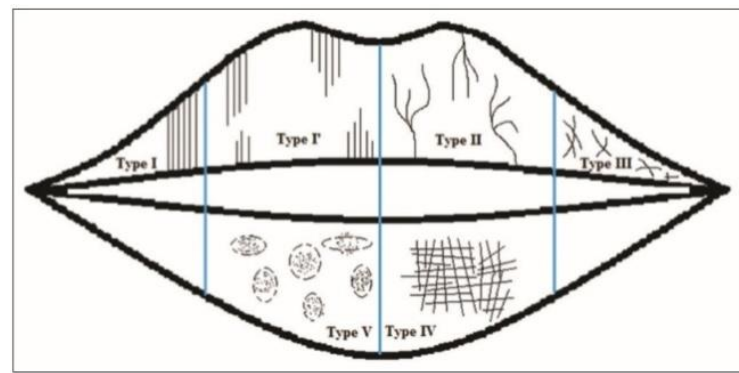

Figure1. Types of lip print from Suzuki and Tsuchihashi classification

The purpose of this study is to differentiate sex based on lip print pattern in Malay population using lipstick-cellophane tape technique. The lipstick-cellophane tape method was used in lifting the lip print, as an improvement of the lipstick paper-cardboard proposed by [8], which could not produce a clear lip print. The lip print identification process is faster and easier compared to DNA testing. Therefore, this research also suggests that lip print identification can be useful as an applicable technique in forensic practical applications. 


\section{METHODOLOGY}

The study comprised of 360 subjects consisting of 180 males and 180 females. They were selected conveniently among Malay population. Subjects with pathological condition such as syphilis, lymphangiomas, congenital lip fistula and Markel son-Rosenthal Syndrome were excluded from the study [9]. Individuals with scar, lip-piercing and dried lips were also excluded because their lip print patterns have changed. Consent were taken from all subjects. Non glossy, less greasy and red coloured lipstick was used for optimum lip print visibility [5]. Wet tissue was given to clean the lip's subject for hygiene purpose. The lipstick (Silky Girl Siren Red Code 01) was applied uniformly on the subject's lips using lip brush with one stroke to avoid smudging of the lip print. It was left to dry for 30 seconds. Transparent cellophane tape $(44 \mathrm{~mm}$ width of Sheng Long Tape) was used and pressed with adequate pressure on the subject's lips. The subjects were asked to relax without stretching their lips to obtain the lip prints. The tape was then removed carefully and placed onto a plain A4 paper. This procedure was repeated three times without reapplying the lipstick. Paper with the subject's lip prints was labeled with details (serial number and date). The visualised lip prints were

Table1. Percentage (\%) distribution of Malay population classified based on the Suzuki and Tsuchihashi classification, using a magnifying glass. The lip print was divided equally into six sections: upper left (UL), upper middle (UM), upper right (UR), lower right (LR), lower middle (LM) and lower left (LL).Data was analysed using Statistical Package Social Sciences (SPSS) to determine the differences in lip print patterns between sexes.

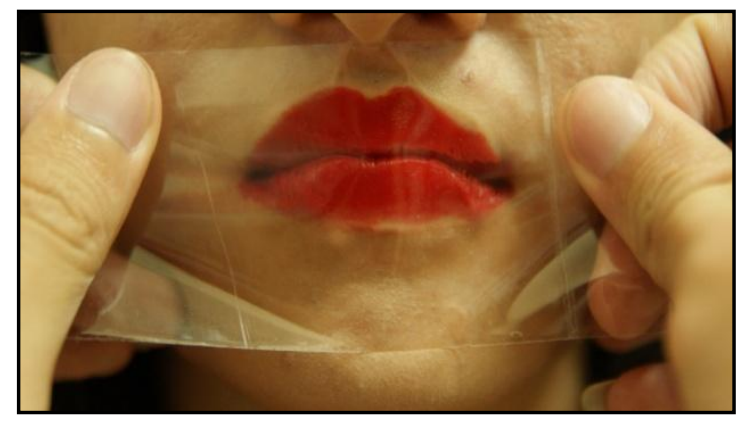

Figure2. Transparent cellophane tape pressed with adequate pressure on the subject's lips[5]

\section{RESULTS AND DISCUSSION}

Table 1 showed the percentage distribution of Malay population in each section of the lip print. Type II was the most dominant type in upper left $(43.9 \%)$, upper right $(41.9 \%)$, lower right $(51.9 \%)$ and lower left sections $(60.0 \%)$ while type IV was dominant in upper middle (53.9\%) and lower middle sections (41.9\%).

\begin{tabular}{|l|l|l|l|l|l|l|}
\hline Lip & Upper Left & Upper Middle & Upper Right & Lower Right & Lower Middle & Lower Left \\
\hline I & 16.4 & 7.2 & 16.1 & 12.5 & 22.5 & 13.9 \\
\hline I' & 9.4 & 8.3 & 13.3 & 8.3 & 12.5 & 3.6 \\
\hline II & 43.9 & 15.0 & 41.9 & 51.9 & 12.8 & 60.0 \\
\hline III & 10.8 & 6.4 & 11.9 & 15.0 & 4.2 & 14.4 \\
\hline IV & 2.8 & 53.9 & 3.1 & 1.9 & 41.9 & 0.8 \\
\hline V & 16.7 & 9.2 & 13.6 & 10.3 & 6.1 & 7.2 \\
\hline
\end{tabular}

Table 2 showed the percentage of distribution of lip print patterns in each section. For upper left section, type II was the dominant pattern in both males and females (28.9\% and 58.9\%) respectively. For upper middle section, the dominant lip print pattern of males $(61.7 \%)$ and females $(46.1 \%)$ was type IV. For upper right section, both males and females showed similar dominant lip print pattern of type II which constituted $35.6 \%$ and $48.3 \%$ respectively.

Table2. Percentage (\%) of distribution of lip print patterns in Malay male and female population

\begin{tabular}{|l|c|c|c|c|c|c|c|}
\hline Types & Sex & UL & UM & UR & LR & LM & LL \\
\hline \multirow{3}{*}{ I } & M & 24.4 & 7.2 & 21.7 & 13.9 & 23.9 & 10.6 \\
\cline { 2 - 8 } & $\mathrm{F}$ & 8.3 & 7.2 & 10.6 & 11.1 & 21.1 & 17.2 \\
\cline { 2 - 8 } $\mathbf{I}^{\prime}$ & $\mathrm{M}$ & 9.4 & 6.1 & 13.3 & 13.9 & 6.1 & 2.2 \\
\hline \multirow{3}{*}{ II } & $\mathrm{F}$ & 9.4 & 10.6 & 13.3 & 12.8 & 18.9 & 5.0 \\
\hline \multirow{3}{*}{ III } & $\mathrm{M}$ & 28.9 & 10.0 & 35.6 & 45.0 & 8.3 & 55.0 \\
\cline { 2 - 8 } & $\mathrm{F}$ & 58.9 & 20.0 & 48.3 & 58.9 & 17.2 & 65.0 \\
\cline { 2 - 8 } IV & $\mathrm{M}$ & 11.7 & 5.6 & 11.1 & 20.0 & 5.6 & 21.1 \\
\hline \multirow{3}{*}{ V } & $\mathrm{F}$ & 10.0 & 7.2 & 12.8 & 10.0 & 2.8 & 7.8 \\
\cline { 2 - 8 } & $\mathrm{M}$ & 3.3 & 61.7 & 2.8 & 3.3 & 50.0 & 1.11 \\
\cline { 2 - 8 } & $\mathrm{F}$ & 2.2 & 46.1 & 3.3 & 0.6 & 33.9 & 0.6 \\
\cline { 2 - 8 } & $\mathrm{M}$ & 22.2 & 9.4 & 15.6 & 13.9 & 6.1 & 10.0 \\
\hline
\end{tabular}


In lower right section, both males and females again showed similar dominant lip print pattern of type II which were $45.0 \%$ and $58.9 \%$ respectively. Both males and females illustrated type IV as the dominant pattern with $50.0 \%$ for males and $33.9 \%$ for females in lower middle section. For lower left section, both males and females showed type II lip print was the dominant type with $55.0 \%$ and $65.0 \%$ respectively. A statistical analysis was performed using SPSS software. Chi-square test was conducted to prove that there were

Table3. The highest percentage of lip print patterns in males and females

\begin{tabular}{|l|l|l|l|l|}
\hline Type & Male & Area & Female & Area \\
\hline I & 24.4 & Upper Left & 21.1 & Lower Middle \\
\hline I' & 13.3 & Upper Right & 18.9 & Lower Middle \\
\hline II & 55.0 & Lower Left & 65.0 & Lower Left \\
\hline III & 21.1 & Lower Left & 12.8 & Upper Right \\
\hline IV & 61.7 & Upper Middle & 46.1 & Upper Middle \\
\hline V & 22.2 & Upper Left & 11.7 & Upper Right \\
\hline
\end{tabular}

The results showed that there were significant differences in lip print of all sections between males and females, which supported by [10] in their project which involved six topography areas and[5, 11, 12]for four topography areas. However, Kinra et al. [13] showed no significant differences between males and females. This was probably because of the small sample size (20 males and 20 females) in their work.

Sonal et al. [12] noted that certain lip print pattern were ubiquitously found in male or female but for this current study, both males and females had similar dominant lip print pattern in each sections of the lips, as noted in $[5,8,14$, 15]. The result showed that type II was the most dominant lip print patterns for both sex in four sections: upper left $(28.9 \%$ for male and $58.9 \%$ for female), upper right (35.6\% for male and $48.3 \%$ for female), lower right ( $45.0 \%$ for male and $58.9 \%$ for female) and lower left (55.0\% for male and $65.0 \%$ for female). Type IV lip print patterns was dominant for upper middle section with $61.7 \%$ for male and $46.1 \%$ for female and lower middle section with $50.0 \%$ for male and $33.9 \%$ for female. For the current study, type II was the most dominant lip print patterns for Malays. This was different from Neo et al. [5] when they noted that type I' was the dominant lip print pattern among Malays. Small sample size might contribute to the disagreement of the results. The current study had 360 samples while Neo et al. had only 88 samples.

\section{CONCLUSION}

There were significant differences in sex based on the lip print patterns in all six sections of the significant differences of two nominal categories which are the sexes and types of grooves. All sections of lip print showed significant differences where $\mathrm{p}<0.05$.

Table 3 showed the highest percentage of lip print patterns in males and females. The highest percentage among all types of lip print patterns in males was type IV with $61.7 \%$ in upper middle section while type II was the highest percentage in females with $65.0 \%$ for lower left section.

lips in Malay population using lipstickcellophane technique. Type II was the dominant lip print patterns for both sexes in Malays. This finding is hoped to give insight into identification process for solving criminal investigations which involves lip print pattern analysis. For future study, a stereo microscope can be used instead of magnifying glass for a clear visualisation of the lip print pattern.

\section{REFERENCES}

[1] Kasprzak, J., Possibilities of cheiloscopy. Forensic Science International, 1990. 46(1): p. 145-151.

[2] Tsuchihashi, Y., Studies on personal identification by means of lip prints. Forensic Science, 1974. 3: p. 233-248.

[3] Caldas, I.M., Magalhaes, T. and Afonso, A., Establishing identity using cheiloscopy and palatoscopy. Forensic Sci Int, 2007. 165(1): p. 1-9.

[4] Ghimire, N., Ghimire, N., Nepal, P., Upadhyay, S., Budhathoki, S.S., Subba, A. and Kharel, B., Lip print pattern: an identification tool. 2014, 2014. 11(3): p. 5.

[5] Neo, X.X., Osman, K., Amir Hamzah, S.P.A. and Noor Hazfalinda, H., Lip Prints in Sex and Race Determination. Jurnal Sains Kesihatan Malaysia, 2012. 10(1): p. 29-33.

[6] Sharma, P., Saxena, S. and Rathod, V., Cheiloscopy: The study of lip prints in sex identification. Journal of Forensic Dental Sciences, 2009. 1(1): p. 24-27.

[7] Jeergal, P.A., Pandit, S., Desai, D., Surekha, R. and Jeergal, V.A., Morphological patterns of lip prints in Mangaloreans based on Suzuki and Tsuchihashi classification. J Oral Maxillofac Pathol, 2016. 20(2): p. 320-7. 
[8] Bindal, U., Jethani, S.L., Mehrotra, N., Rohatgi, R.K., Arora, M. and Sinha, P., Lip prints as a method of identification in human beings. Journal of the Anatomical Society of India, 2009. 58(2): p. 152-155.

[9] Thomas, C.J. and van Wyk, C.W., The palatal rugae in an identification. $\mathrm{J}$ Forensic Odontostomatol, 1988. 6(1): p. 21-7.

[10] El Domiaty, M.A., Al-gaidi, S.A., Elayat, A.A., Safwat, M.D. and Galal, S.A., Morphological patterns of lip prints in Saudi Arabia at Almadinah Almonawarah province. Forensic Sci Int, 2010. 200(1-3): p. 179.e1-9.

[11] Nagrale, N., Bipinchandratirpude, Murkey, P. and Patond, S., Establishing Cheiloscopy as a Tool for Identification: An Assessment on 500 Subjects In Central India. Al Ameen Journal of Medical Sciences, 2014. 7(3): p. 201-206.
[12] Sonal, V., Nayak, C.D. and Pagare, S., Study of Lip-prints as aid for sex determination. Medico-Legal Update, 2005. 5(3): p. 7-9.

[13] Kinra, M., Ramalingam, K., Sethuraman, S., Rehman, F., Lalawat, G. and Pandey, A., Cheiloscopy for Sex Determination: A Study. Journal of Dentistry, 2014. 4(1): p. 48-51.

[14] Augustine, J., Barpande, S.R. and Tupkari, J.V., Cheiloscopy as an adjunct to forensic identification: a study of 600 individuals. J Forensic Odontostomatol, 2008. 26(2): p. 4452.

[15] Verghese, A.J., Somasekar, M. and Umesh Babu, R., A Study on Lip Print Types among the People of Kerala. Journal of Indian Academic of Forensic Medicine, 2010. 32(1): p. 6-7.

Citation: Wan Rafiuddin Wan Ahmad, Sri Pawita Albakri Amir Hamzah, Noor Hazfalinda Hamzah. Sex Differentiation by Lip Print Analysis in Malays: Lipstick-Cellophane Tape Techniques. ARC Journal of Forensic Science. 2018 3(1):18-21. http://dx.doi.org/10.20431/2456-0049.0301004

Copyright: (C) 2018 Authors. This is an open-access article distributed under the terms of the Creative Commons Attribution License, which permits unrestricted use, distribution, and reproduction in any medium, provided the original author and source are credited. 